\title{
Foreign Aid Reduces Labor Supply and Capital Accumulation
}

\section{Liutang Gong, Heng-fu Zou}

In an optimal growth model with foreign aid, foreign borrowing, and endogenous leisure-and-consumption choices, it is shown that a permanent rise in foreign aid reduces long-run capital accumulation and labor supply, increases long-run consumption, and has no effect on long-run foreign borrowing.

See http://onlinelibrary.wiley.com/doi/10.1111/1467-9361.00110/abstract 